\title{
LA PRIMERA CAMPAÑA DE EXCAVACIÓN EN LA IGLESIA DE SANTA MARIA DE MATADARS O DEL MARQUET $^{1}$
}

\section{La premier campagne de fouilles a l'église de Santa María de Matadars ou de le Marquet}

\author{
Alberto López Mullor y Àlvar Caixal Mata* \\ Recibido el 12 de febrero de 2008. Aceptado el 20 de marzo de 2008.
}

Resumen. Durante los años 2003 y 2004 y algunas semanas de 2008, nuestro servicio ha llevado a cabo sendas campñas de excavación en la iglesia de Matadars, en calidad de fase preliminar de la restauración de este edificio prerrománico. En 1934, en el marco de una primera intervención, se descubrireron algunas ruinas atribuidas a la nave lateral norte de la iglesia -hoy día inexistente, como la meridional-, pero nuestra investigación es la primera que se puede calificar de verdaderamente arqueológica.

De momento, hemos descubierto la presencia de vestigios de una villa romana en el subsuelo de la iglesia, además de una importante necrópolis asociada a los primeros siglos de vida del templo. Por otra parte, hemos fechado su fundación entre los últimos años del siglo IX y principios del $X$, a partir del análisis tipológico y estratigráfico de sus fábricas y de los materiales arqueológicos aportados por la excavación. También se ha determinado la reconstrucción de la iglesia durante el segundo cuarto del siglo XI, momento en que adoptó las líneas maestras de su aspecto actual. La investigación ha proporcionado además numerosas noticias sobre la posterior evolución del templo hasta nuestros días.

Palabras clave: Matadars. Marquet. Villa. Iglesia. Prerrománica. Románica.

Résumé. En 2003 et 2004 et pendant quelques semaines de 2008, notre service a mené à bien des campagnes de fouilles à l'église de Matadars, comme phase préliminaire de la restauration de ce bâtiment préroman. L'an 1934, dans le cadre d'uns premiers travaux, on a déjà découvert quelques ruines attribuées à la nef latérale nord-aujourd'hui inexistance, comme celle du sud-mais notre recherche c'est la première qu'on peut qualifier de vraiment archéologique.

Pour l'instant, nous avons découvert la présence de vestiges d'une villa romaine, au sous-sol de l'église, ainsi qu'une important nécropole associée aux premiers siècles de vie du temple. D'ailleurs, nous avons daté sa fondation aux dernières années $d u$ IX $X^{e}$ siècle ou au début du Xe, à partir de l'analyse typologique et stratigraphique de ses fabriques, et des matériaux apportés par la fouille. On a déterminé aussi la reconstruction de l'église lors du deuxième quart du XI siècle, lorsqu'elle a adopté les grandes lignes de son aspect actuel. En outre, la recherche a proportionné aussi des nombreuses nouvelles au sujet de la postérieure évolution du temple jusqu'à nos jours.

Mots clef: Matadars. Marquet. Villa. Église. Préromane. Romane.

(') En memoria de nuestro maestro, el profesor Eduardo Ripoll Perelló, quien siempre nos animó a estudiar la iglesia de Matadars.

$\left({ }^{*}\right)$ Servicio de Patrimonio Arquitectónico Local. Diputación de Barcelona. Comte d'Urgell, 187. 08036-Barcelona, lopezmal@diba.es; caixalma@diba.es 


\section{SITUACIÓN Y DESCRIPCIÓN}

La iglesia de Santa Maria de Matadars o del Marquet está situada al oeste del término municipal de El Pont de Vilomara i Rocafort (Barcelona), dentro de la urbanización Marquet Paradis y sobre una terraza fluvial de la orilla izquierda del río Llobregat. Su acceso se realiza por el kilómetro 4 de la carretera local BV-1229, de Sant Vicenç de Castellet a El Pont de Vilomara, que enlaza con la autopista C-16, de Barcelona a Manresa. Conviene advertir que, hasta no hace mucho, el templo pertenecía al vecino término municipal de Mura, y con tal referencia aparece en numerosas publicaciones.

El edificio está compuesto de dos elementos diacrónicos (fig. 2-7). La cabecera prerrománica, formada por un santuario central de planta rectangular y dos capillas laterales cuadradas que constituyen los dos brazos del transepto, y la nave románica, que se adaptó a la cabecera original con una ostensible desviación hacia el nordeste. Los muros del santuario son de sillares alargados e irregulares unidos con mortero de cal, apreciándose en el tramo inferior de su fábrica algunas hiladas de opus spicatum (fig. 9). Está cubierto por una bóveda de sección de herradura rebajada, en cuyo intradós se aprecian las marcas del encañizado que sirvió de cimbra al construirla. La cubierta de la nave es de cañón (fig. 11). En el eje de la fachada de levante se abre una ventana rectangular de recorrido vertical, coronada por un arco de herradura cuyas dovelas son losas de piedra alargadas y algunos fragmentos cerámicos. El pavimento es de losas irregulares, colocadas durante la última intervención arquitectónica que sufrió el edificio, en 1974. Entonces también se añadió un altar formado por una losa colocada sobre un dado exento construido con piedras escuadradas, que fue desmontado en 2004, en el curso de la intervención actual. Este espacio comunica con el transepto a través de un arco triunfal de herradura (fig. 11). También adoptan tal morfología los dos arcos menores que unen el crucero con las capillas laterales que forman los dos trazos del transepto.

La septentrional (fig. 12) está cubierta por una bóveda de cañón construida sobre cimbra de encañado, que ha dejado trazas bien visibles. Conserva un altar macizo de piedra adosado al muro oriental, donde se abre una ventana rectangular y alargada, a modo de aspillera. Hacia poniente se observa, tapiado por un paño más moderno de piedras pequeñas y cuadradas, el arco de herradura que embocaba la antigua nave lateral prerrománica. La capilla lateral de mediodia ha llegado a nosotros mutilada y arrasada. Tan sólo quedan en pie algunas hiladas de sus muros perimetrales aunque conserva los restos de un pavimento de losas de piedra irregulares. Cabe añadir que en el área de la cabecera se conserva un transepto elevado, que descansa sobre el crucero, a modo de cimborio (fig. 1-3, 9).

En la nave, cubierta por una bóveda de cañón que arranca de sendas líneas laterales de imposta y que está reforzada por dos arcos fajones, el aparejo es sensiblemente más regular que el de la cabecera y está formado por hiladas de sillarejo colocados a soga y tizón. Se encontraba pavimenta$\mathrm{da}$, al igual que la cabecera, con losas de piedra irregulares colocadas modernamente, que se han ido extrayendo en el curso de nuestra excavación. El paso de la nave al ámbito del transepto y la cabecera se realiza a través de un escalón de piedra (fig. 11). Los muros meridional y septentrional del aula presentan cada uno dos ventanas de doble derrame acabadas en arcos de medio punto adovelados. Igualmente en su último tramo aparecen, a una altura aproximada de metro y medio, una serie de orificios cuadrangulares que recuerdan a los mechinales. En el aula se observa también un banco corrido, añadido en época reciente, que se adosa a los muros que la flanquean, así como un arcosolio abierto en el extremo oriental del muro norte. Está formado por dovelas labradas en cuyo interior aparece un banco adosado tanto a la pared lateral de la nave como al arco triunfal. En el ángulo noroeste del aula se conserva una pila bautismal de piedra. También debe destacarse que en el intradós de la bóveda del aula, en el tramo situado entre el último arco fajón y la cabecera, se conservan los restos muy deteriorados de una decoración pictórica realizada con pigmentos negros y rojos sobre una base de enfoscado de cal. Su composición se basa en la repetición de un motivo ornamental, unas casillas o cuadrículas que imitan el despiece de sillares, en el interior de los cuales aparece inscrita una especie de palmeta dotada de un tallo central (fig. 11). Su cronología no se ha fijado claramente hasta ahora, aunque se han atribuido a un momento posterior a la fábrica románica y anterior al siglo XVI. ${ }^{2}$

Por último, en la fachada de poniente se abre un portal sencillo acabado en arco de medio punto compuesto por dovelas extradosadas por una hilera de losetas, y una ventana en forma de cruz, abierta con motivo de unas reformas llevadas a cabo en 1974. Sobre el hastial se conservan, muy deteriorados, los restos de una pequeña espadaña de un solo ojo con sombrerete y moldura de imposta (fig. 8).

\section{ANTECEDENTES}

La iglesia de Matadars o del Marquet es un edificio bien conocido dentro de la arquitectura prerrománica catalana. ${ }^{3}$ A causa de su interés, ya había sido objeto de atención por parte de nuestro Servicio, que llevó a cabo obras en 1934. Después el conjunto sufrió otras intervenciones menos benéficas, por no decir francamente dañinas, que alteraron al- 
gunas partes de sus fábricas de manera irreversible, según explicaremos más adelante. En los últimos tiempos, el hecho de que el edificio fuese una propiedad particular había dificultado la realización de una nueva intervención, muy necesaria, teniendo en cuenta el lamentable estado en que se encontraba. Desde 1991, se sucedieron los trámites para proseguir su restauración. Primero, desde el Ayuntamiento de Mura, y a partir de 1994, desde el del Pont de Vilomara i Rocafort, a raíz de que, mediante un decreto del Departamento de Gobernación de la Generalitat de Catalunya, la masía del Marquet y la iglesia pasasen al territorio de este otro municipio. De este modo, el 19 de marzo de 2003, el Ayuntamiento del Pont de Vilomara i Rocafort, obtuvo la cesión temporal de uso del templo mediante convenio con su propietario. Acto seguido, el 6 de junio del mismo año, la Diputación acordó con el Ayuntamiento la restauración de la iglesia, que empezó en agosto.

\section{OBJETIVOS Y MÉTODO}

Teniendo en cuenta estos antecedentes, que ponian de relieve que el yacimiento estaba lejos de permanecer intacto, los objetivos de la investigación arqueológica, enmarcada dentro del conjunto de estudios históricos previos a la redacción del proyecto de restauración, se centraron en excavar, en primer lugar, aquellas partes del exterior de la iglesia que habian de verse afectadas inmediatamente por las obras. Así, se actuó en el lugar donde debía anclarse el apuntalamiento de la pared meridional, en grave peligro de derrumbe, y también en una amplia superficie del entorno oriental y septentrional. En estos lugares era de suma importancia conocer los estratos asociados al edificio, que hasta entonces no se había fechado con claridad, así como la posible existencia de una necrópolis. Además, se pretendia documentar la presencia del muro septentrional de la nave lateral norte prerrománica, cuyas ruinas se habian puesto al descubierto en el transcurso de las obras de 1934, según indicaban algunas fotografias (fig. 8). En el interior del edificio, confiábamos en encontrar sedimentos in situ en la nave y en la cabecera, y en poder efectuar una "reexcavación" de los lugares afectados por obras anteriores, con el objetivo de registrar, cuando menos, la posición estratigráfica de los elementos arquitectónicos que han pervivido.

Los trabajos se llevaron a cabo en diferentes campañas a lo largo del año 2003 y parte de 2004, bajo la dirección de quienes suscriben con la colaboración de Anna Gómez Bach. El estudio de los restos óseos humanos hallados en la necrópolis se realizó por un equipo de la facultad de Ciencias de la Universidad Autónoma de Barcelona, formado por Thaïs Fadrique i Susana Carrascal, bajo la dirección de A. Malgosa. La dirección general de la intervención en el monumento corre a cargo del arquitecto jefe del Servicio, Antoni González Moreno-Navarro, en colaboración con los arquitectos Joan Closa, Xavier Guitart y la arquitecta técnica Fina Gener.

Como puede verse en las figuras 2 a 7, paralelamente a la excavación de las zonas que se han indicado más arriba, se realizó la lectura estratigráfica de los paramentos del edificio, cuyos resultados finales presentamos en las citadas ilustraciones. Como se sabe, este tipo de estudios son habituales en las investigaciones arqueológicas de nuestro Servicio. ${ }^{4}$

\section{DESCRIPCIÓN DE LA INVESTIGACIÓN}

En el mes de agosto de 2003, nuestro Servicio llevó a cabo diversos apuntalamientos en la fachada de mediodía del edificio. Esta intervención fue precedida por la excavación de los dados donde debían situarse los cimientos de las estructuras metálicas. En noviembre y diciembre del mismo año se inició la excavación y el desmontaje de las cubiertas del presbiterio y de la capilla norte de cabecera, se construyó un andamio en el interior de la nave, que también servía para apuntalar su bóveda, y se llevó a cabo la consolidación de las pinturas murales. A lo largo de 2004 comenzó la intervención en el monumento propiamente dicha, poniéndose en marcha la excavación arqueológica del yacimiento, que afectó parte del interior de la iglesia: los elementos de la cabecera y la parte de la nave no afectada por el andamiaje, así como el entorno de levante. Además, se actuó en otros puntos del recinto, tanto para valorar la extensión del área arqueológica intacta, como para poder determinar el alcance de la obra de restauración arquitectónica. De este modo, se abrió una serie de catas frente a la fachada de poniente de la iglesia, con la doble intención de localizar los límites del cementerio parroquial e identificar los restos de un chalet, construido en 1943 y demolido treinta años después. Debe destacarse que estos sondeos evidenciaron que los cimientos de tal construcción habian destruido un gran número de enterramientos de la sagrera. Al mismo tiempo, se excavaron seis catas de $3 \mathrm{~m}^{2}$ cada una en el sector noroeste, donde estaba previsto modificar el terreno para abrir el futuro camino de acceso a la iglesia. Todas resultaron estériles.

Siempre conforme a los criterios metodológicos mencionados, la aparición de una extensa necrópolis a levante de la cabecera del templo propició la colaboración con nuestro equipo del ya citado equipo de la facultad de Ciencias de la Universidad Autónoma, que se encargó de la extracción de los individuos inhumados, así como de su posterior estudio en el laboratorio. Poco después, las sepulturas, una vez documentadas y consolidadas, fueron cubiertas provisionalmente.

(4) Cf. p.e.: Caixal 1997; Fierro 1997; López Mullor 1986; 1987; 2002. 
Cabe decir que, en la parte de la sagrera donde se halló el mayor número de tumbas, que abarcaba todo el entorno oriental del edificio, también aparecieron, según veremos, numerosos silos y los vestigios de un edificio relacionado con la iglesia. El entorno occidental, ya se ha dicho, estaba completamente removido. En el septentrional quedaban vestigios al nordeste, donde se siguieron encontrando tumbas y silos y el arranque del antiguo muro lateral de la nave prerrománica de aquel lado. En el entorno meridional, que se ha excavado en 2007, en paralelo al recalce del maltrecho muro sur de la na$v e$, ha aparecido una estrecha franja intacta, con algunas tumbas medievales posteriores al siglo XI, dos silos anteriores a esta fecha y vestigios de un lacus perteneciente a la pars rustica de una villa romana anterior a la iglesia.

En el momento de escribir estas líneas, continúan los trabajos de recalce del muro meridional de la nave, lo que conlleva la laboriosa realización de una serie de catas arqueológicas previas al vertido de la sucesivas tandas de hormigón. Al finalizar este proceso, esperamos intervenir en el resto del aula, así como en el subsuelo del brazo sur del transepto, dando así por acabada nuestra actuación en el edificio que, en cualquier caso y como siempre, no culminará hasta haber finalizado el control arqueológico de las próximas obras de restauración.

\section{CONCLUSIONES}

\section{Horizonte $A$, t.a.q. siglo $X$}

A lo largo de las campañas de excavación de 2003 y 2004, aun no habiéndose hallado estructura antigua alguna en el yacimiento, se constató la presencia de materiales arqueológicos de filiación romana en los estratos contemporáneos de la fundación de la iglesia. Siempre fuera de contexto, aparecieron fragmentos dispersos de cerámica común de la Tarraconense o de procedencia itálica y africana, así como diversos materiales constructivos, tales como restos de opus signinum, tegulae o lateres. Incluso, se localizó un bloque de piedra, que servía de base al ángulo nordeste del brazo septentrional del transepto, sin duda reaprovechado, que parecía proceder de un torcularius. Por fin, en el transcurso de la campaña de 2007, se ha descubierto la esquina de un posible lacus o simplemente de un lagar, a juzgar por la cubeta de decantación que presenta, construido con opus signinum. Esta estructura, muy maltrecha por una tumba medieval posterior, se encontraba encajada en el terreno natural (fig. 13). Además, en los sondeos abiertos en el lado meridional de la nave de la iglesia, previos al recalce del muro sur, aparecieron in situ estratos romanos. Se trataba de capas de regularización, vertidas para nivelar los limos naturales que en este punto, ya en la antigüedad, de- bieron presentar una brusca pendiente hacia el sur. Todo este material hay que relacionarlo con la existencia en el lugar de una villa romana, la Villa Amarus, hipótesis ya planteada por diversos autores a partir de la etimología de los topónimos que se citan en las fuentes documentales, y ahora confirmadas por la arqueología.

Del mismo modo, en el yacimiento han aparecido cerámicas grises de pastas bien depuradas y con decoraciones geométricas. Corresponden a las primeras producciones locales datadas hacia el final de la antigüedad tardía o en los primeros tiempos de la edad Media, bien conocidos, por ejemplo, en la ciudad de Barcelona, donde se fechan en los siglos VIII-X. ${ }^{5}$ Estos materiales esporádicos, permiten constatar la continuidad de la ocupación del sitio a lo largo del bajo imperio romano y de la alta edad media. A esta etapa deben corresponder dos silos amortizados en el momento de la construcción de la iglesia prerrománica, uno situada debajo de los cimientos de la fachada meridional de la cabecera y otro abierto en el paso de la nave al transepto.

\section{Horizonte B, t.a.q. 956}

El 5 de enero de 955 se hace referencia al término de la ville de Matadarcus, situado en Néspola, denominación antigua de parte del término de Pont de Vilomara i Rocafort y también del de Mura, en un documento de venta de una viña por parte de María y sus hijos a Cesáreo, abad del monasterio de Santa Cecilia de Montserrat. Un año más tarde, en 956, Ansulfo da al abad Cesáreo unas tierras del condado de Manresa, cerca del río Llobregat, donde está la villa de Matadars, con unas iglesias, altares y otros santuarios. ${ }^{6}$

Según los resultados proporcionados por la investigación arqueológica, en un momento por ahora indeterminado, quizá entre los decenios finales del siglo IX o principios del siglo $X$, tuvo lugar la fundación del edificio prerrománico de tres naves de la iglesia de Santa Maria de Matadars. Pertenecen a esta fábrica primitiva, construida como se ha dicho más arriba con un aparejo de piedras alargadas poco labradas que forman toscas hiladas, en el que, según los tramos, aparecen sectores de opus spicatum, la actual cabecera de planta rectangular con bóveda de sección en herradura, así como los dos espacios avanzados de planta trapezoidal que cumplen la función de brazos del transepto (fig. 5). Éstos albergaban sendas capillas laterales y estaban cubiertos por una bóveda de cañón bastante tosca construida sobre cimbra de cañizo, que sólo se conserva en el elemento septentrional pues el meridional la perdió hace tiempo.

Tampoco han quedado restos en alzado de la nave principal ni de las dos laterales del edificio prerrománico. Las obras llevadas a cabo por nuestro Servicio en 1934 pusieron

(5) Beltrán de Heredia 2006.

(6) Si no se indica otra cosa, las referencias a la documentación escrita se han extraído del trabajo de investigación documental realizado por nuestro Servicio en paralelo a la investigación arqueológica: David, Puig (inédito). 
en evidencia los cimientos del muro de cierre de la nave norte (fig. 8), que ahora sólo hemos redescubierto parcialmente, pues fueron mutilados en 1974. Además, en el curso de la investigación actual, mediante una cata previa al recalce del ángulo suroeste del edificio, se han descubierto pequeños vestigios de los cimientos de lo que pudo haber sido el testero occidental del edificio religioso primitivo.

El pavimento del santuario principal y las capillas laterales era de losas de piedra local de diferentes tamaños, talladas irregularmente y unidas con abundante mortero de cal. Desde la nave se accedía a través de un escalón, muy deteriorado por posteriores intervenciones, formado por piedras rectangulares unidas con mortero de cal. De la misma cronología y textura es el escalón de acceso a la capilla lateral norte. En la nave, de momento, parece haberse identificado algún resto del suelo primitivo que, en este caso sería de cal mezclado con arena y gravilla. En todo caso, los futuros trabajos en el aula terminarán de confirmar si esta textura era la original.

Contemporáneos de la primera fábrica del templo eran diez silos abiertos en los moldeables limos naturales. Se han descubierto, tanto en el interior del edificio, donde aparecieron dos en el brazo septentrional del transepto, al pie del altar (fig. 12), otros dos en el subsuelo de la antigua nave sur $y$, de momento, uno en la central, como en el exterior, donde se han excavado cinco en el sector nordeste de la sagrera. Presentaban perfiles muy similares, de sección esférica o semiesférica alargada con el fondo siempre plano. En el entorno septentrional del templo, siempre dentro del área de unos treinta pasos en derredor considerada como sagrada e inviolable, aun habiéndose percibido la presencia de silos, no ha sido posible delimitar su planta nitidamente, al haber sido muy afectados por las fosas de una necrópolis de inhumación posterior $y$, sobre todo, por los movimientos de tierra efectuados a lo largo de la segunda mitad del siglo XX.

La estratigrafía demostró que todos esos silos fueron amortizados en los primeros años del siglo Xl, coincidiendo con la importante remodelación que sufrió el espacio del templo reservado a los fieles, pasando de tres naves a una sola y estrechándose considerablemente. De este modo, los depósitos fueron rellenados con bloques de piedra, fragmentos de teja, cenizas y carbón vegetales, conservando en tres casos sus tapas de piedra depositadas en el fondo. De cualquier modo, el ejemplo más interesante de relleno de dos de estos depósitos apareció en el extremo oriental de la actual nave sur. En este punto, al haberse de apoyar parte de los cimientos del aula sobre la boca de dos silos, éstos fueron rellenados sistemáticamente de piedras colocadas en hiladas y unidas con mortero de cal, que dieron a la pared el sólido apoyo que precisaba. El relleno de uno de los silos adquirió un curioso aspecto de estructura negativa, al ser retirado durante la excavación un sector de la parte superior de su pared, a causa de la apertura de un sondeo geotécnico.
De la misma época que este campo de silos era una necrópolis situada en el entorno inmediato de la cabecera del templo prerrománico (fig. 10). Se identificaron trece sepulturas, utilizadas una sola vez y agrupadas en hileras junto a la fachada de levante, excepto dos, que adoptaban una disposición topográfica de norte a sur condicionada por el resto de enterramientos. Estaban orientadas de este a oeste, con el cuerpo del inhumado en decúbito supino, cuyos brazos se encontraban semiflexionados sobre la pelvis o el tórax, 0 extendidos a lo largo del cuerpo; la cabeza se hallaba a poniente. Todas las tumbas eran de planta rectangular, a veces trapezoidal u ovoide, y se trataba de cajas de losas dispuestas en seco, cubiertas con grandes piezas del mismo tipo, dispuestas horizontalmente y selladas con arcilla y cal. La cabecera tenía trazado antropomorfo, realizado con guijarros o losas pequeñas dispuestas en cuña verticalmente. El fondo de las sepulturas cortaba horizontalmente el terreno natural, sin evidencias de la existencia de lecho de losas ni de capas que nivelasen el sustrato geológico. A pesar de la similitud tipológica que presentaban todas ellas, se diferenciaron dos fases temporales en la disposición de los enterramientos, correspondientes, eso sí, al mismo horizonte cronológico. Esta diferenciación, que afectaba a cinco sepulturas, que parecian más tardias que el resto, se concretó teniendo en cuenta su distribución topográfica y su disposición dentro de las relaciones estratigráficas del conjunto, y no sus rasgos tipológicos, ya que, desde este punto de vista, las diferencias con el resto eran casi inexistentes. Quizá, una pequeña evolución del sistema de enterramiento se podría intuir a través de la presencia en estas últimas tumbas de paredes laterales formadas por piedras superpuestas de factura irregular y pequeñas losas. Cabe añadir que la tumba adosada a la fachada de poniente del templo, aunque no pudo excavarse del todo, era de características muy similares a las de levante, lo que ayudó a su clasificación y datación.

\section{Horizonte $C$, siglo $X I$}

Una parte del edificio fue modificada en el siglo XI utilizando el estilo románico. De este modo, las tres naves iniciales fueron sustituidas por una sola, cubierta por una bóveda de cañón reforzada con arcos fajones, y con acceso a poniente (fig. 6). Este hecho queda patente en la fábrica de la nave, aparejada con sillarejo dispuesto en hiladas a soga y tizón, lo que le confiere un aspecto bastante más ordenado y regular que el de la fase anterior. La nueva aula se adaptó a la cabecera original con una notable desviación hacia el nordeste. En su fachada de poniente se abrió un portal sencillo acabado en arco de medio punto formado por dovelas extradosadas por una hilera de losas (fig. 8).

No se ha podido recuperar ningún elemento de los que culminaban la cubierta original de esta nave, ni tan sólo improntas de las losas que probablemente la formaban. Sin em- 
bargo, se han identificado los restos muy deteriorados de las capas de regularización de los niveles situados por encima del extradós de la bóveda, cuya fábrica está compuesta por piedras y losas planas, colocadas a manera de pliego de libro y unidas con mortero de cal mezclado con un poco de arena y mucha grava fina, procedente de los sustratos geológicos de las terrazas del Llobregat.

La investigación arqueológica ha puesto en evidencia las banquetas de fundación de los muros septentrional y meridional de la nave. También ha permitido localizar los vestigios de su pavimento primitivo, formado por losas de factura irregular unidas con mortero de cal, más delgadas que las conservadas sobre ellas que, como veremos, son del siglo XX. En esta fase se amortizaron los silos situados en el interior del templo (fig. 12) y dentro de la sagrera, al norte del templo. La cerámica hallada en sus rellenos aporta suficiente información como para datar las reformas románicas hacia mediados del siglo XI. Además, debe mencionarse la presencia, en el entorno meridional de la iglesia, en el subsuelo de la primitiva y desaparecida nave colateral sur, de tres silos. Dos de ellos fueron amortizados con un relleno compacto de piedras y argamasa, por encontrarse justamente debajo de la cimentación meridional de la nueva nave única románica, y el tercero fue rellenado con tierras y piedras, como es usual al abandonar este tipo de depósitos.

A esta época también pertenece un conjunto de enterramientos situados en el entorno septentrional de la iglesia. Esta ubicación, forzada por la densidad de inhumaciones que ya existían al abrigo del santuario principal, comportó que las nuevas sepulturas cortaran numerosos silos de la fase anterior, ya amortizados. A través de su tipología, estas sepulturas pueden datarse en los siglos XI y XII. Se trata de fosas simples con los extremos redondeados, cortadas en el terreno natural, $y$ con una cubierta de losas planas, la mayoría de las veces expoliada o rota. Todos los individuos habían estado dispuestos en posición de decúbito supino dentro de la estructura funeraria, con la cabeza hacia el oeste y los pies hacia el este.

En cuanto a la teoría recogida por la historiografía de que la iglesia podría haber sido incendiada en 1002, como consecuencia de la incursión sarracena d'Abd Al - Malik, ${ }_{1}^{7}$ la excavación ha constatado la presencia de restos constructivos de desecho, cenizas y carbones abundantes en los estratos de amortización de los silos y en los rellenos de las trincheras de fundación de las banquetas de los muros de la nave románica, lo que podría corroborar la hipótesis del incendio o de una destrucción violenta. Sin embargo, la fecha de este acontecimiento, con los materiales de que ahora disponemos, a falta de la excavación de la nave, ${ }^{8}$ sólo puede situarse en un momento anterior a mediados del siglo XI.

\section{Horizonte D, principios del siglo XIII}

Aunque la investigación arqueológica no ha constatado ninguna reforma en el interior de la iglesia -donde, como se ha dicho, la excavación de la nave, está prácticamente por hacer-, los trabajos en el entorno de levante y mediodía han permitido documentar la existencia de un edificio de planta cuadrada y una serie de estructuras anexas de dificil interpretación. Estos elementos, con todo, cabría relacionarlos con las dependencias agropecuarias derivadas de la explotación de las tierras del Mas Marquet, que desde el 1201 aparece en la documentación escrita. También sería posible que tales estancias correspondiesen a una casa parroquial, pues la sucesión de curas párrocos conocidos a través de las fuentes documentales -siempre dependientes del monasterio de Montserratempieza en el siglo XIII, época en que, por otra parte, esta clase de edificios parece empezar a construirse por doquier.

Conocemos dos de los muros que delimitaban esta construcción y los restos del estribo de un arco diafragmático que subdividia su estancia principal en dos crujías, como mínimo, y que también indica la presencia de un piso alto apoyado en éste y otros soportes del mismo tipo. Tal solución constructiva, el aparejo de los muros, de sillares bien escuadrados dispuestos en hiladas regulares, y los materiales cerámicos aparecidos en los estratos fundacionales, nos permiten datar la construcción de esta casa en el siglo XIII, en un momento en que la zona situada junto a la cabecera de la iglesia dejó de ser el lugar principal de enterramiento. El cementerio se trasladó entonces al entorno de poniente, absolutamente arrasado en 1943, al construirse una casa de veraneo.

\section{Horizonte E, siglo XIV}

El arcosolio abierto en el muro norte de la nave debería pertenecer a este período, dadas su morfología y factura. Es apuntado y está construido con dovelas grandes, bien escuadradas y abujardadas, lo que le proporciona un terminus post quem del siglo XIV. Las pinturas murales con motivos florales, todavía sin datar pero anteriores al siglo XVIII, de las que se conservan algunos vestigios sobre el arco, constituyen su terminus ante quem.

La investigación arqueológica ha constatado que en aquella época se colocó un hogar dentro del edificio descubierto al sudeste de la iglesia. Estaba acompañado de un depósito para almacenar cenizas procedentes de la combustión. Además, alrededor de esta construcción se dispusieron algunas capas de tierra para nivelar el suelo. De la misma fase data un elemento muy degradado, que hemos identificado como los restos de un sepulcro cubierto por una bóveda de piedra y rodeado de un pavimento de losas. Su posición, adosado al

(7) Junyent 1983: 126; Villegas 1983: 59

$\left.{ }^{8}\right)$ En el momento de escribir estas líneas, nuestro Servicio procede al recalce del muro sur del aula, en grave peligro de colapso. Una vez realizados estos trabajos y terminada la restauración de la cubierta del edificio, donde ya se ha excavado, podremos emprender la investigación arqueológica del subsuelo de la nave, actualmente cubierto por un bosque de puntales que sostienen su bóveda. 
lado de mediodía de la cabecera, y su factura constructiva permiten situar su fecha, en el paso del siglo XIII al XIV.

\section{Horizonte F, segunda mitad del siglo XVI}

De este período no constan actividades edilicias que afectasen a la estructura del templo o a la fisonomía de los lugares de culto. Con todo, en el curso de la excavación se ha documentado la aportación de diferentes capas de tierra tanto en el interior -asociadas a pequeñas reparaciones del pa-

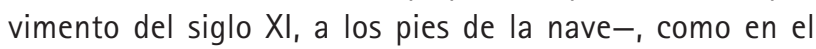
exterior del edificio. En este último caso, se trata de la regularización de las cotas de uso en los sectores de levante y tramontana, y lo que es más importante, del abandono de la construcción situada al sudeste de la iglesia. En la misma época se produjo la amortización del sepulcro adosado a la pared sur de la cabecera, al construirse una escalera de piedra para acceder al cuerpo elevado del crucero, entonces reformado y convertido en una estancia. Debe tenerse presente que la documentación escrita de la época se refiere al mal estado de conservación en el que se encontraba el edificio: en la actualización de una relación del patrimonio de Santa María de Montserrat, efectuada entre 1564 y 1578 se mencionaba que "la iglesia está muy derruida y sin clérigo".

\section{Horizonte G, siglo XVIII}

La mayoría de la información referida a este período la conocemos a través de la documentación escrita. En el acta de la visita pastoral de 1726 se cita el templo como Santa Eulalia de Matadars, seguramente debido al retablo de estilo gótico que presidía su interior, con la figura de la santa pintada en la tabla central, flanqueada por san Sebastián y san Juan Bautista. Este retablo estuvo en el altar mayor hasta 1912 y hoy se conserva en el Museo Nacional de Arte de Cataluña, al que llegó después de haber estado en manos privadas.

Sabemos, además, que al menos hasta 1751, la iglesia continuaba manteniendo la categoría de parroquia. Con todo, y debido a una reestructuración parroquial emprendida por el monasterio de Montserrat en sus posesiones, desde 1799, el templo pasó a ser una simple capilla, dependiente del párroco de Monistrol de Montserrat. Bien entrado el siglo XVIII, tal y como dedujimos del material cerámico encontrado en su estrato fundacional, se alzó un pajar adosado al Mas Marquet, lo que contribuyó a la destrucción de la estratigrafía asociada a esta casa y sus anexos, fechados en el siglo XIII.

\section{Horizonte $H$ e I, siglos $X I X$ y $X X$}

En 1822, con motivo de la supresión de las órdenes religiosas, la iglesia de Matadars pasó a depender de la de San
Vicenç de Castellet, que a su vez dependía de la parroquia de San Vicenç de Castellbell. A raíz de las leyes de desamortización de los bienes eclesiásticos de 1836 y 1837, propuestas por el ministro de Hacienda Juan Álvarez Mendizábal, en 1854 la iglesia, ya desacralizada, pasó a manos de la familia Casajoana, propietaria del Mas Marquet, y desde entonces su propiedad ha estado ligada a la de esta explotación rural.

En 1931, el edificio fue declarado Monumento Histórico-Artístico. Desde algunos años antes, en 1925-26 y 1928, en las memorias de nuestro Servicio, denominado entonces de Catalogación y Conservación de Monumentos y dirigido por el arquitecto Jeroni Martorell, se había argüido la necesidad de su restauración. Por fin, en 1934 y bajo la dirección del propio Martorell, se inició la primera etapa de trabajos en la iglesia, entonces propiedad de Pere Calsina. Las obras consistieron en el saneamiento de la escalera que accedía al cuerpo elevado del crucero, la apertura de la ventana del ábside, hasta entonces tapiada, y la construcción de una nueva cubierta de teja árabe en la cabecera y en la capilla norte del crucero. Se repasaron también el resto de las cubiertas de la iglesia (fig. 9). Hay constancia de que se removieron grandes cantidades de tierra en su entorno septentrional, descubriéndose de este modo las dos o tres hiladas inferiores de una gran parte del muro lateral de la nave colateral norte prerrománica (fig. 8). Al parecer, los vestigios encontrados fueron consolidados mínimamente $y$ vueltos a enterrar. Aquel mismo año se plantó un jardín alrededor de la cabecera, con unos cuantos parterres, y se limpió el interior del templo. ${ }^{9}$

En 1941, Joan Sala Ferrer compró la finca del Marquet o de Matadars y dos años más tarde construyó un chalet de veraneo frente al testero occidental de la iglesia, sobre los restos de la necrópolis de poniente, de época medieval y moderna, que fue destruida sin miramientos. También se colocó entonces un depósito de agua cilíndrico sobre la bóveda del crucero, así como un pequeño canal de desagüe, que descendía por las escaleras adosadas a mediodía de la cabecera. En 1952, las hijas de Joan Sala, fallecido en 1944, iniciaron, asesoradas por el abogado manresano Xavier Sitjes, algunas obras en la iglesia. De esta suerte, se eliminaron la bóveda del crucero y el depósito de agua que se le apoyaba, se repasaron el tejado y los paramentos exteriores de los muros norte y sur y se construyó una acera adosada a las fachadas. A mediodía, se formó un muro de contención, que sirvió de anclaje lateral a una escalera que recorría todo el entorno sur del edificio, salvando el desnivel existente entre sus dos extremos. ${ }^{10}$

En 1962, con motivo de la celebración del X Congreso Internacional de Arte de la Edad Media, en Barcelona, nuestro Servició procedió a la adecuación y la limpieza de la igle-

(9) Sitjes 1977: 137, 139; Junyent 1983: 125; Lacuesta 1998: 570

(10) Sitjes 1977: 140, 143; Lacuesta 2000: ficha 070. 
sia y su entorno, aunque no hay noticias concretas sobre sondeos o movimientos de tierra. En 1973, las antiguas propietarias vendieron la finca a Comercial Castellet S.A. Su representante legal, Salvador Moratonas, aconsejado por Sitjes, llevó a cabo obras en la iglesia y su entorno. En el exterior del templo se volvió a repasar el tejado, especialmente el de la cabecera, y se repararon algunas grietas de las fachadas. Además, en el testero occidental se abrió una ventana cruciforme, que nunca había existido, y se reparó la escalera de piedra que conducía al cuerpo elevado.

En el interior de la iglesia se rehizo el pavimento de losas de la nave y el transepto, colocándose piezas muy gruesas, que prácticamente destruyeron el anterior, visible en la figura 11, así como los poco potentes estratos medievales depositados en este lugar. En el santuario, donde el suelo era menos consistente, de tierra, cal y piedrecitas, las mismas losas acabaron con él. También se repicó el revestimiento de los muros de la nave y se pintó de blanco la cabecera. Finalmente, se añadió un banco de piedra adosado a los muros perimetrales del aula. En el exterior se derribó el chalet construido en 1943 frente a la iglesia, y se formaron dos terrazas que destrozaron parte de las ruinas del muro septentrional de la nave prerrománica norte, descubiertas en 1934 (fig. 7), exceptuando un pequeño tramo de su extremo oriental, redescubierto en nuestra excavación. Del resto, sólo ha quedado memoria a través de las fotografías (fig. 8).

\section{BIBLIOGRAFÍA}

Beltrán de HeREDIA, J. (2006): "Los contextos altomedievales de la plaza del Rey de Barcelona: la cerámica de tradición carolingia". Quaderns d'Arqueologia i Història de la Ciutat (Barcelona), 02: 109-139.

BARRAL, X. (1980): Les pintures murals romàniques d'Olèrdola, Calafell, Marmellar i Matadars. Barcelona.

BARRAL, X. (1981): L'art pre-románic a Catalunya. Segles IX-X. Barcelona.

Benet, A.; Junyent, F.; Mazcuñan, A.; Barral, X.; Sureda, J.; Carbonell, E.; LLARȦS, C. (1984): "Santa Maria de Matadars (o del Marquet)". Catalunya Románica, XI. El Bages. Barcelona: 328-334.

CAIXAL, À. (1997): "El monument, document. Sessió científica celebrada a Barcelona el 21 de març de 1996. Metodologia i anàlisi arqueològica del monument. Un exemple pràctic: el pont de Periques, a Puig-reig". Quaderns Científics i Tècnics, 9, Diputació de Barcelona. Servei del Patrimoni Arquitectònic Local. Barcelona: 356-359.

FierRo, J. (1997): "El monument, document. Sessió científica celebrada a Barcelona el 21 de març de 1996. Algunas reflexiones y experiencias de la práctica arqueológica en edificios". Quaderns Científics i Tècnics, 9, Diputació de Barcelona. Servei del Patrimoni Arquitectònic Local. Barcelona: 352-355.

Gali, D.; PuIG, J. (inédito): Estudi Històric (documental, constructiu i artístic) de l'església de Santa Maria de Matadars (El Pont de Vilomara i Rocafort). Diputació de Barcelona, Servei de Patrimoni Arquitectònic Local. Barcelona.

JUNYENT, E. (1983): L'arquitectura religiosa a Catalunya abans del romànic. Barcelona.

LACUESTA, R. (2000): "Mura. Església de Santa Maria del Marquet o de Matadars". Restauració monumental a Catalunya (segles XIX i XX).
Les aportacions de la Diputació de Barcelona, vols. II-III (CD anexo), Diputació de Barcelona, Servei de Patrimoni Arquitectònic Local, Monografies, 5. Barcelona: fitxa 070.

LÓPEz MULLOR, A. (1986): "Consideracions metodològiques sobre l'actuació del Servei de Catalogació arqueològica". Memória 1984. Diputació de Barcelona. Servei de Catalogació i Conservació de Monuments. Barcelona: 19-21.

López MulloR, A. (1990): "Set anys d'investigació arqueològica del patrimoni arquitectònic». Memória 1985-1989, Diputació de BarceIona, Servei del Patrimoni Arquitectònic. Barcelona, 1990: 13-18.

LóPEZ MULLOR, A. (1997): "El monument, document. Sessió científica celebrada a Barcelona el 21 de març de 1996. Estudi arqueològic del conjunt del castell de Castelldefels (Barcelona)". Quaderns Científics i Tècnics, 9, Diputació de Barcelona. Servei del Patrimoni Arquitectònic Local. Barcelona: 325-350.

LÓPEZ Mullor, A. (2002): "Veinte años después". Arqueología de la Arquitectura (Vitoria), 1, 2002: 159-174.

López Mullor, A.; Fierro, J.; Enrich J.; Enrich, J. y Beltrán de Heredia, J. (2004): "Cerámica tardorromana y medieval en la provincia de Barcelona. Siglos VII-X". Cerámicas tardorromanas y altomedievales en la Península lbérica. Ruptura y continuidad (Segundo Simposio de Arqueología. Mérida, 2001), Anejos de Archivo Español de Arqueología, XXVIII. Madrid: 41-66.

SITJES Molins, X. (1977): Les esglésies pre-romàniques de Bages, Berguedà i Cardener. Manresa.

Villegas Martínez, F. (1983): El romànic del Bages. Estudi dels edificis religiosos. Manresa (2a edición). 


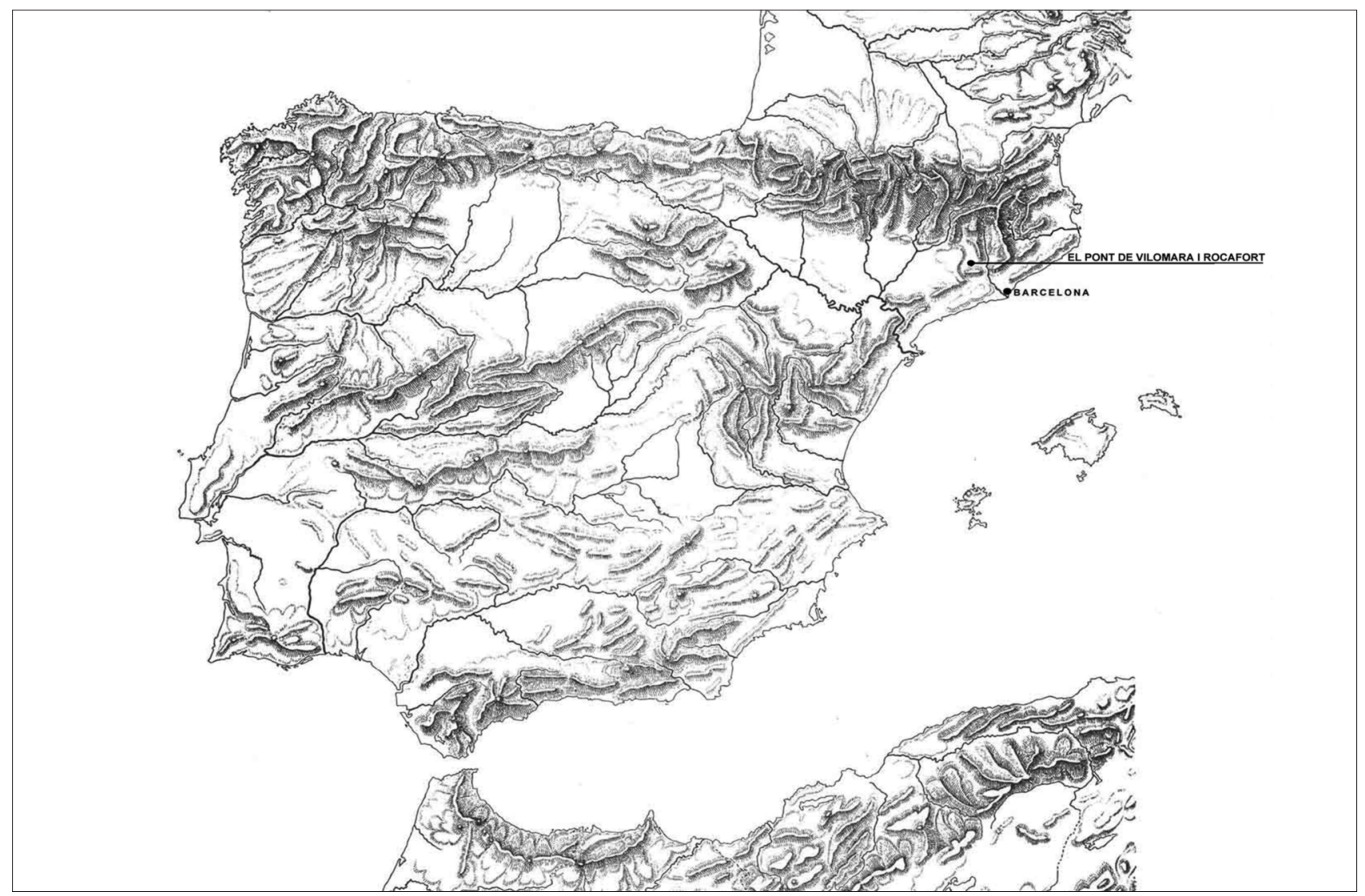

A Figura 1. Situación de la iglesia de Santa María de Matadars (El Pont de Vilomara i Rocafort, Barcelona) en la Península Ibérica.

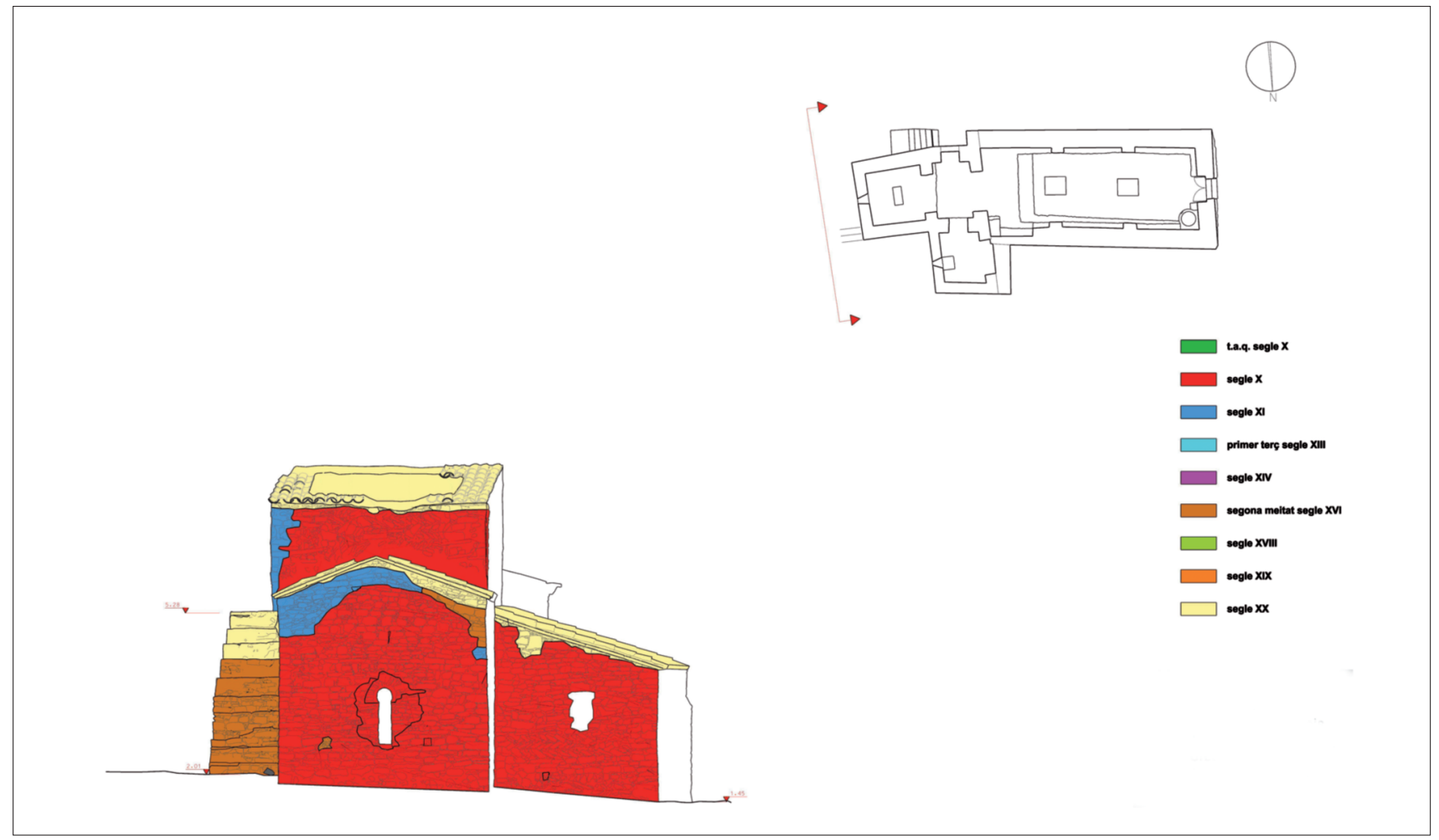

- Figura 2. Alzado de la fachada oriental de la iglesia con indicación cromática de los diferentes horizontes cronológicos. 


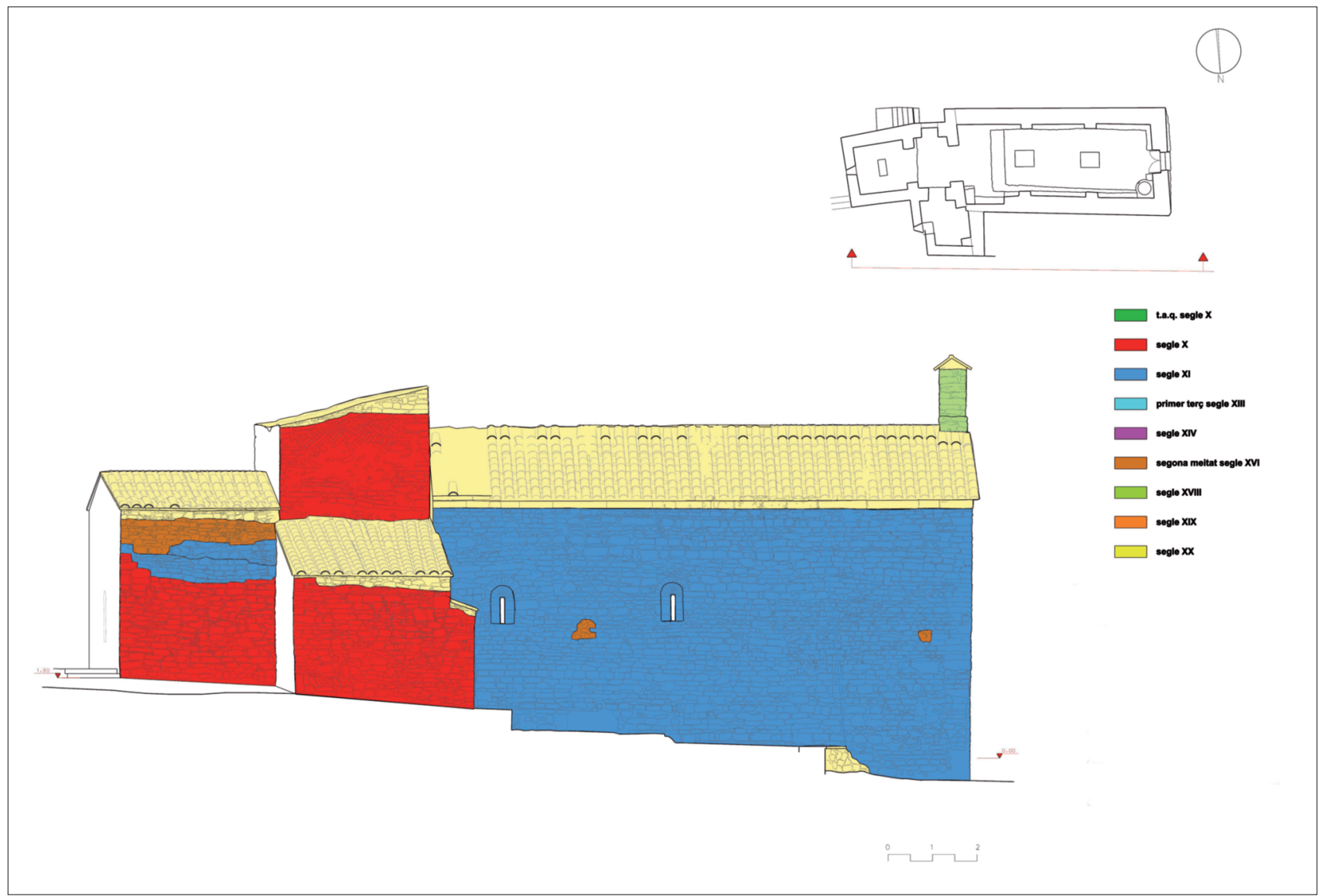

A Figura 3. Alzado de la fachada septentrional de la iglesia con indicación cromática de los diferentes horizontes cronológicos.

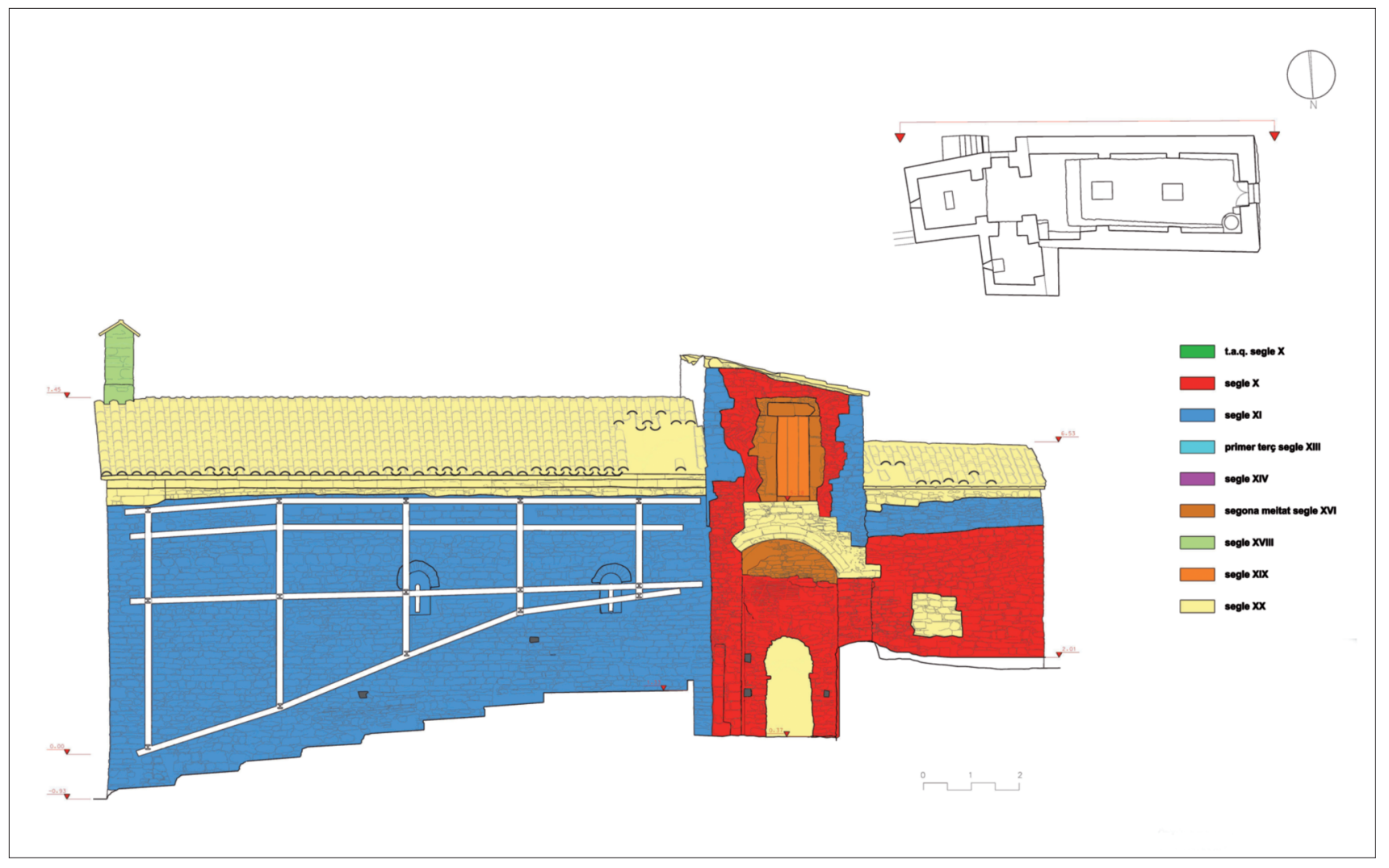

A Figura 4. Alzado de la fachada meridional de la iglesia con indicación cromática de los diferentes horizontes cronológicos.

(๑) UNED. Espacio, Tiempo y Forma. Serie I, Nueva época. Prehistoria y Arqueología, t. 1, 2008. 


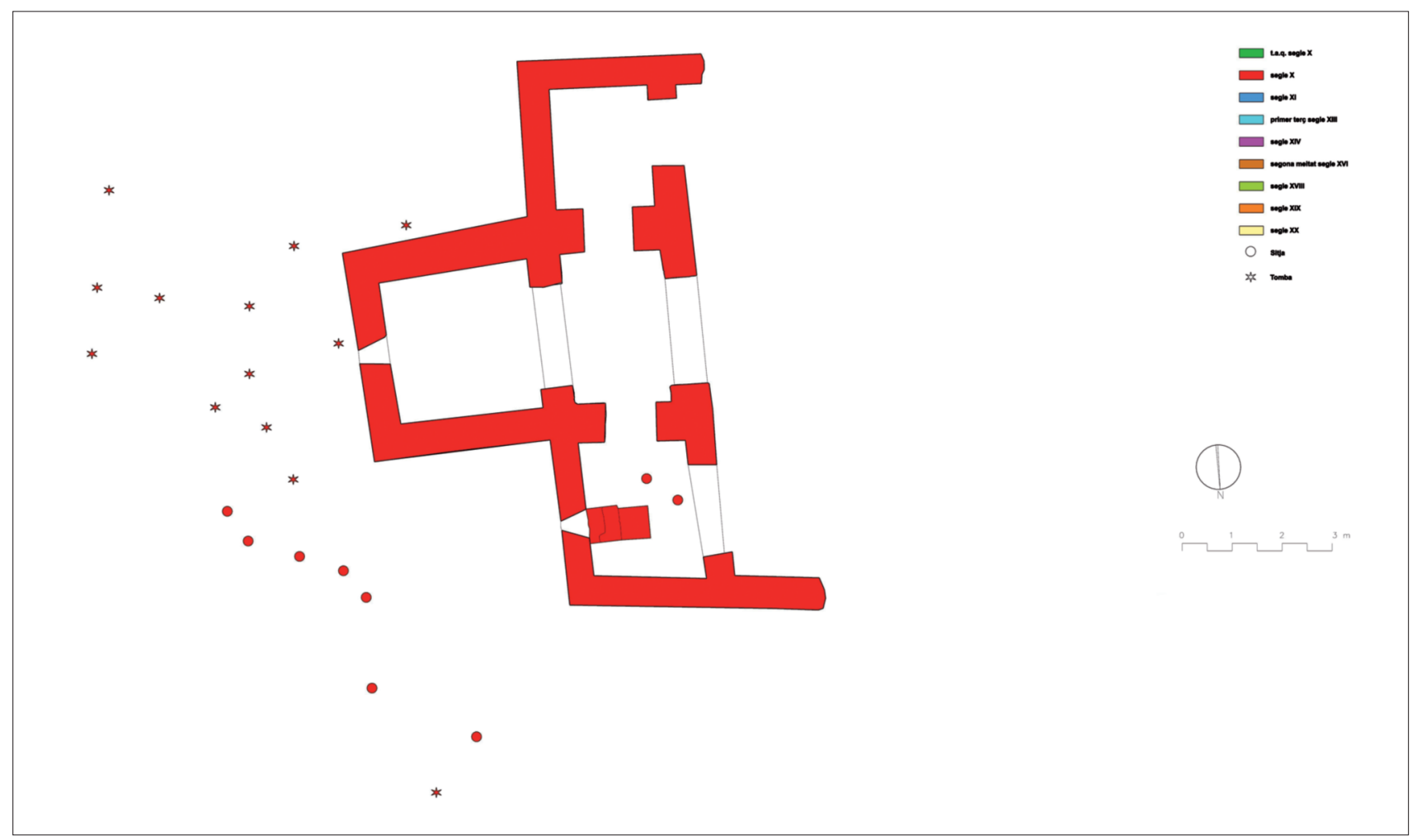

A Figura 5. Planta esquemática de las fases de evolución de la iglesia. Horizonte B: siglos IX-X.
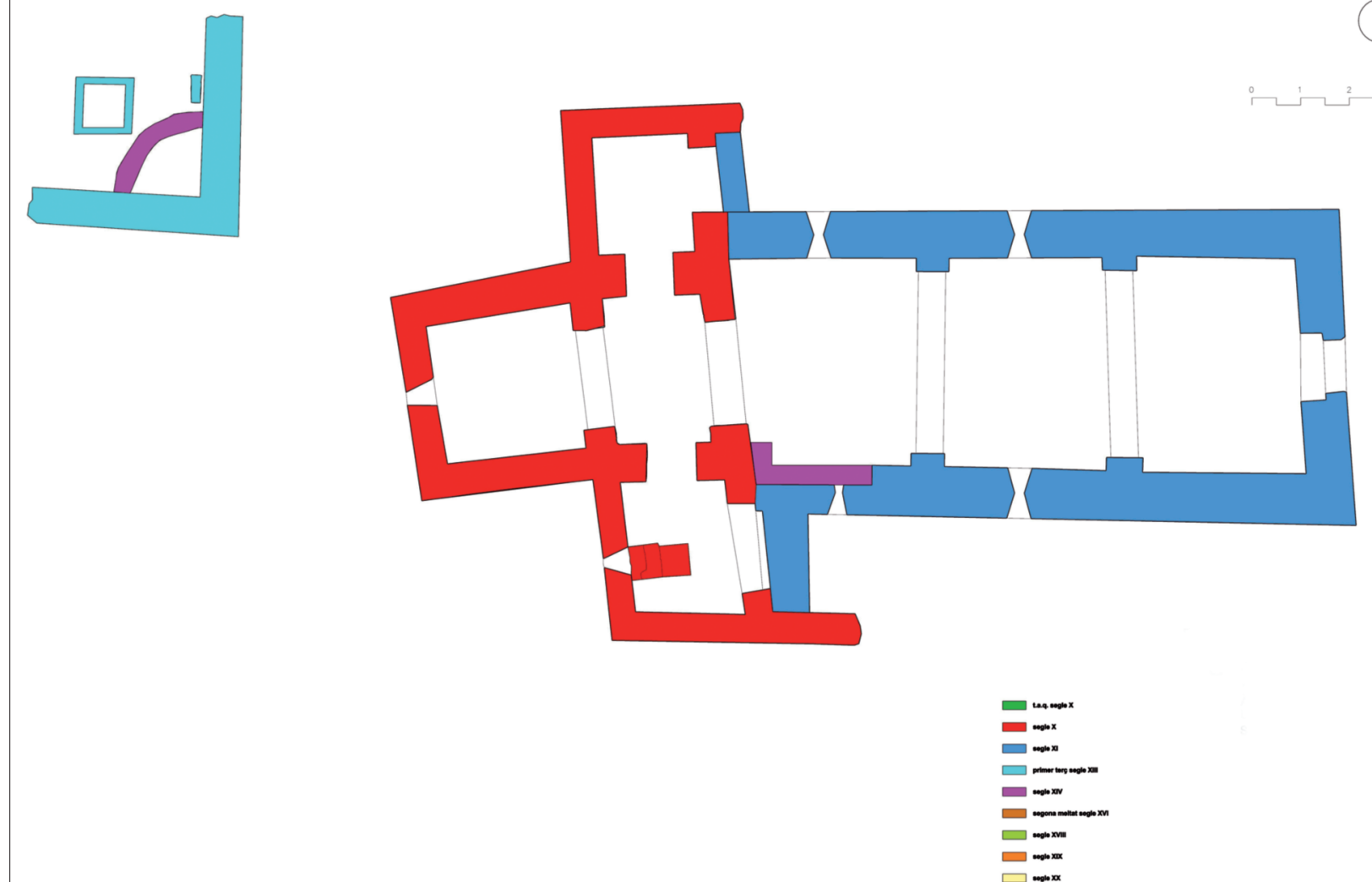

- Figura 6. Planta esquemática de las fases de evolución de la iglesia. Horizontes C-E. Construcción de la nueva nave en el siglo XI, del edificio del sudeste en el XIII y pequeñas modificaciones en los siglos XIV y XV. 


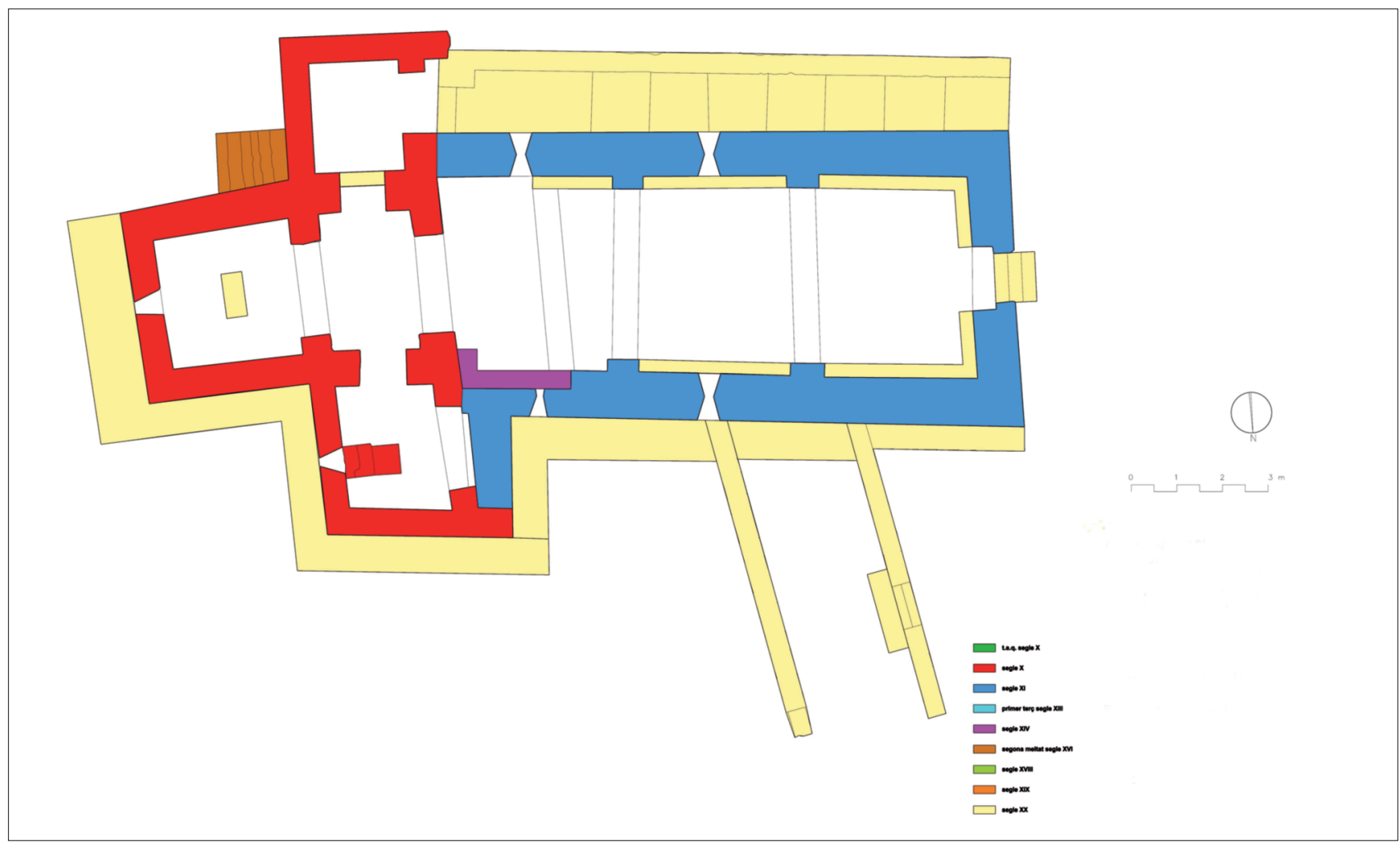

A Figura 7. Planta esquemática de la iglesia en el estado que presentaba al inicio de la intervención actual, en 2003, con indicación cromática de sus diferentes etapas cronológicas.

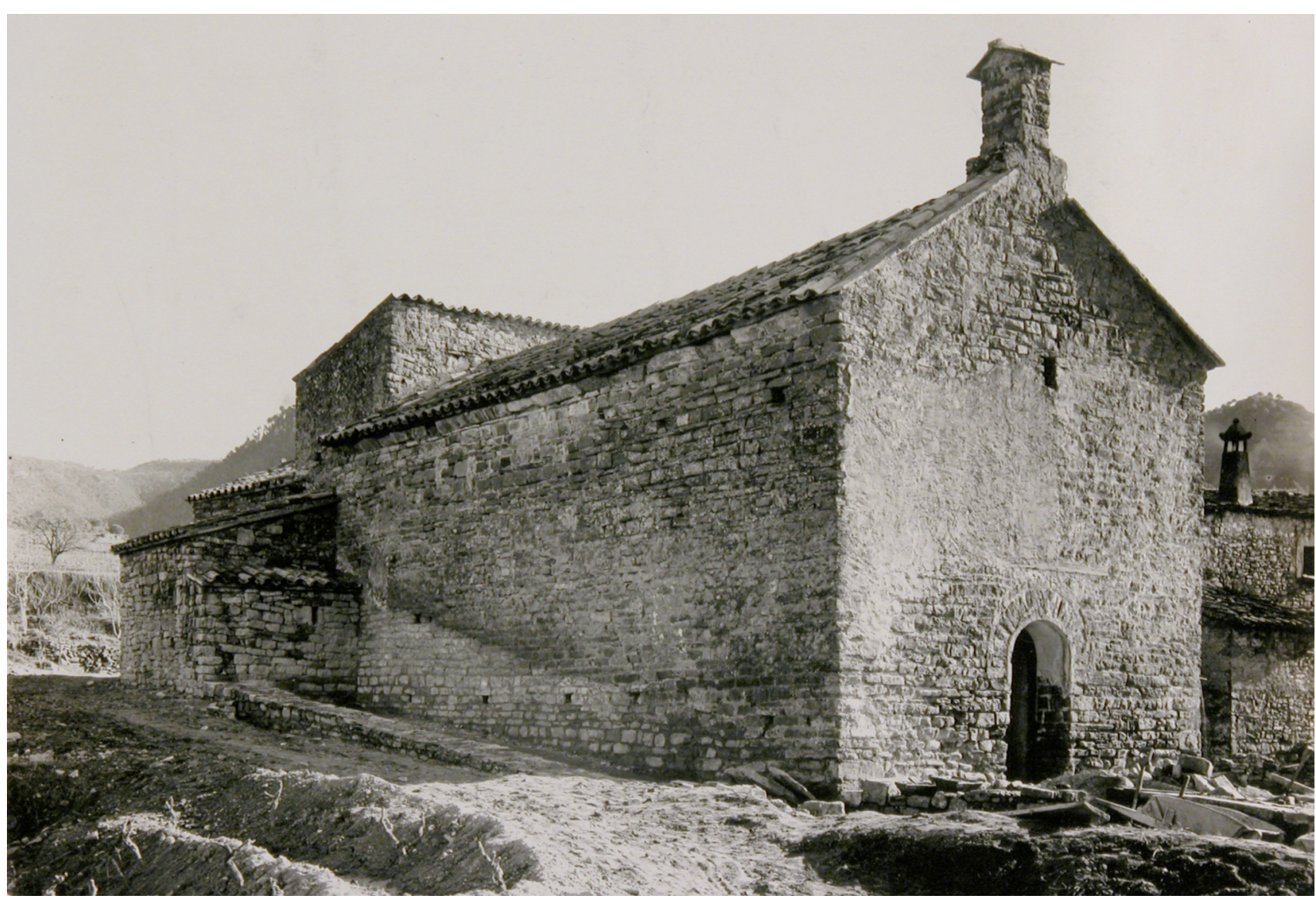

A Figura 8. La fachada septentrional de la iglesia y el testero occidental, en el transcurso de las obras de restauración efectuadas por el Servicio en 1934. En primer término, los restos del muro norte de la nave prerrománica. Foto: fondo documental del SPAL.

348 UNED. Espacio, Tiempo y Forma. Serie I, Nueva época. Prehistoria y Arqueología, t. 1, 2008. 


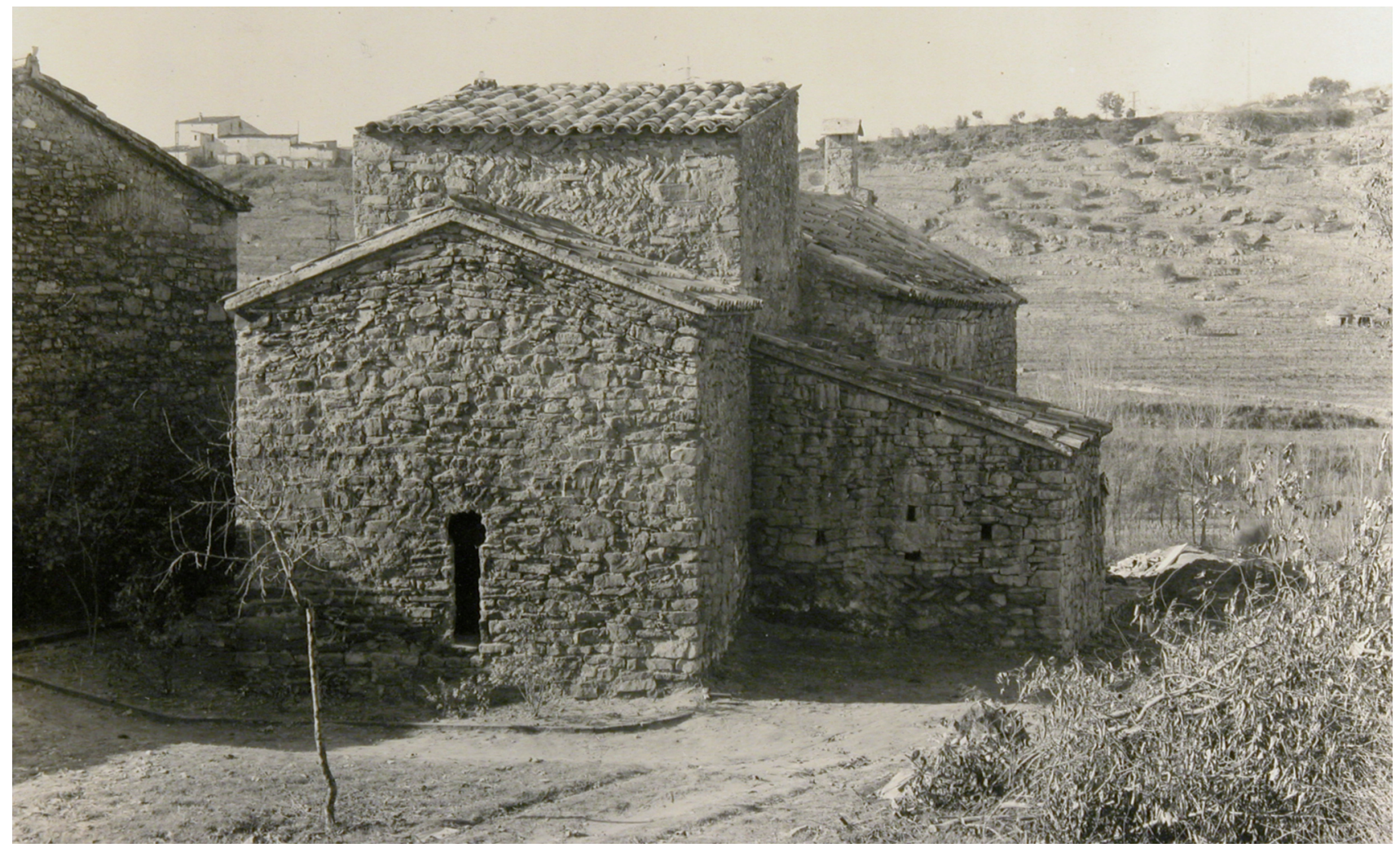

\ FiguRa 9. La iglesia desde levante, poco después de finalizar las obras de restauración efectuadas por el Servicio en 1934. Foto: fondo documental del SPAL.

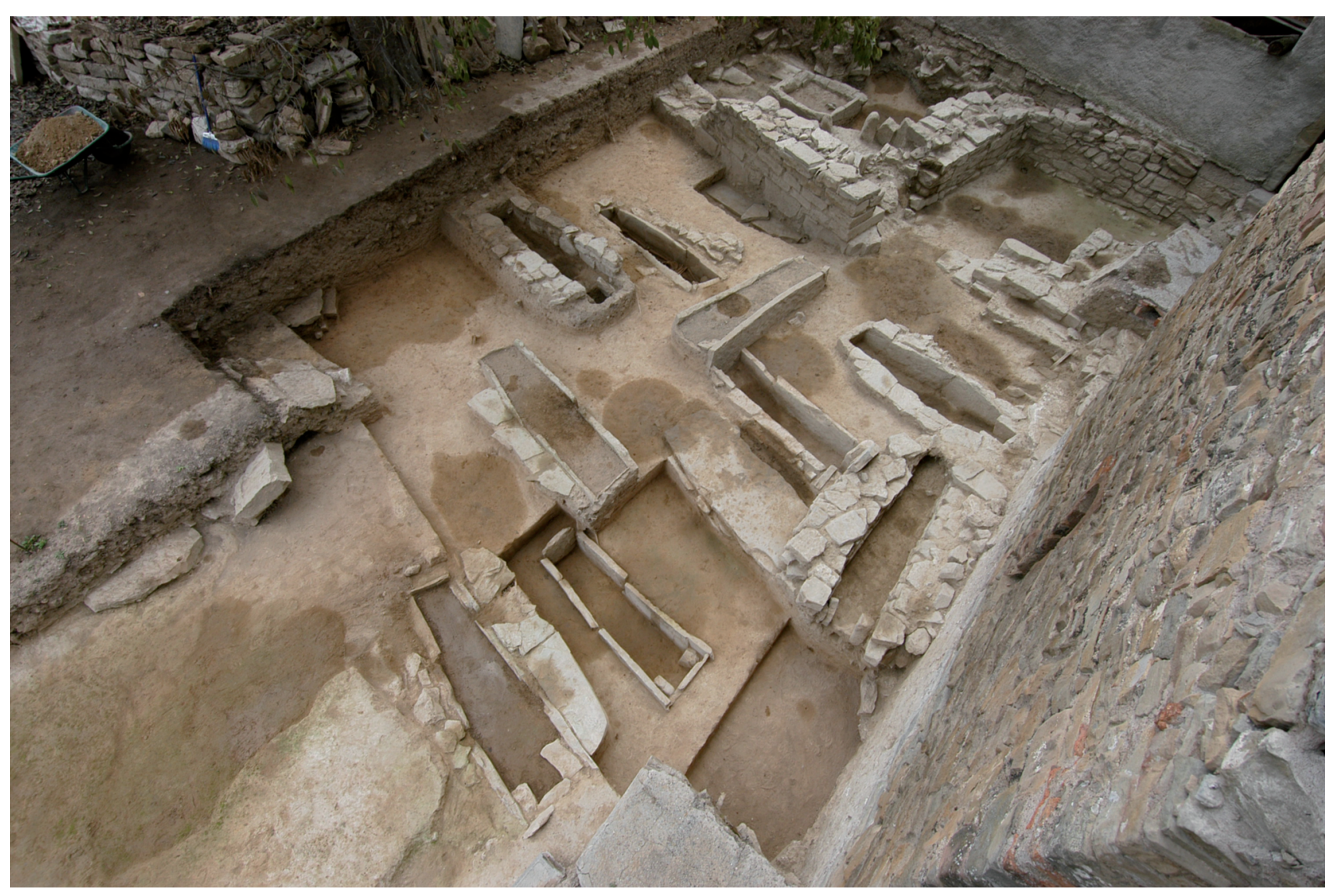

A FiguRa 10. Detalle del entorno oriental del edificio en el curso de la excavación arqueológica. En primer término las tumbas de la Sagrera, y al fondo los vestigios del edificio del siglo XIII. Foto: fondo documental del SPAL. Montserrat Baldomà, 2004. 


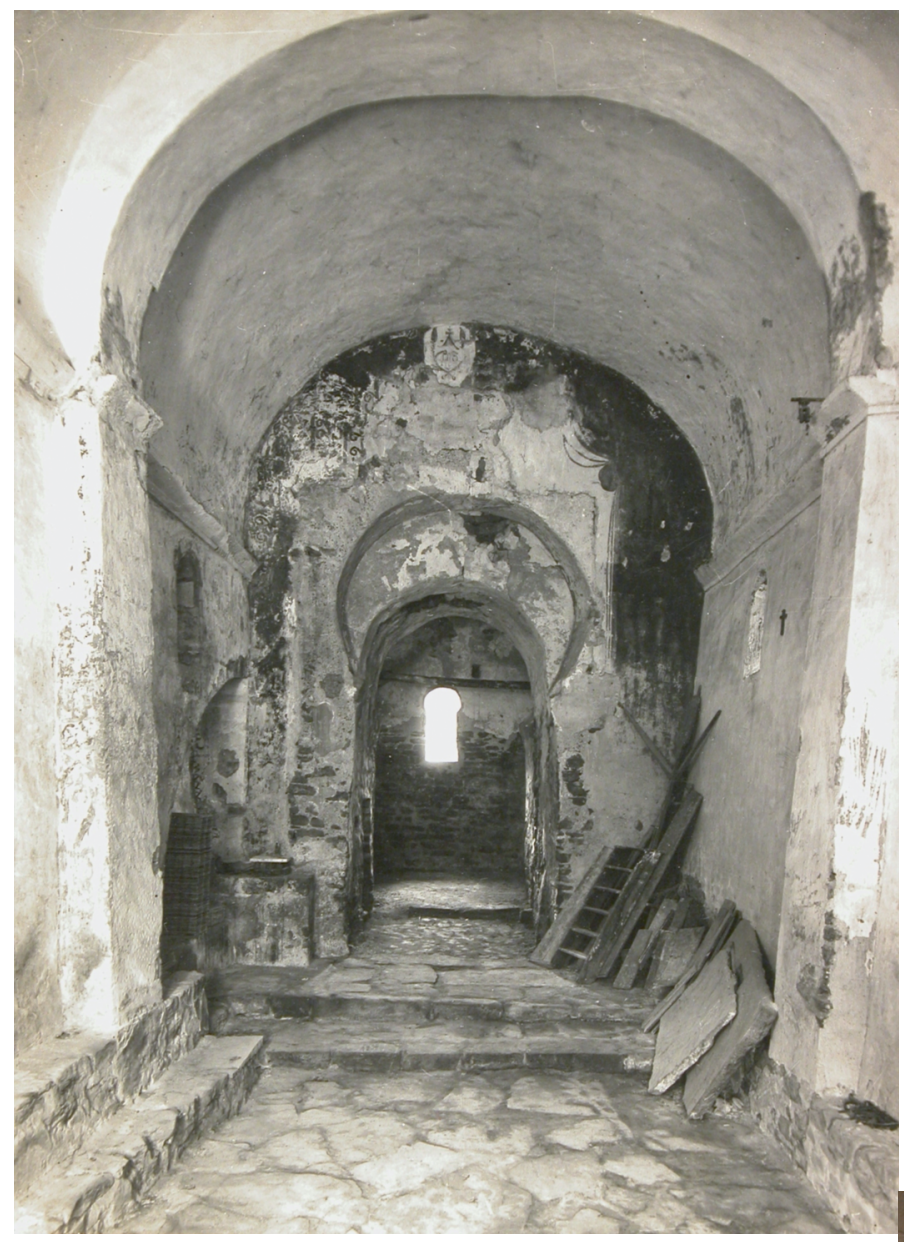

A Figura 11. Interior de la iglesia en la época de la primera intervención de nuestro Servicio (1934). En primer término, la nave románica. Al fondo el arco de herradura que da acceso al crucero, y el presbiterio, situado en el elemento central de la cabecera. Foto: fondo documental del SPAL. Joan Estorch, 1934.

- Figura 12. La capilla situada en el brazo septentrional del transepto, una vez acabada la investigación arqueológica. En primer término, dos silos, amortizados en el siglo XI, a la derecha, el altar primitivo, y a la izquierda, la embocadura de la primitiva nave lateral norte, tapiada en el siglo XI. Foto: fondo documental del SPAL. Montserrat Baldomà, 2004.

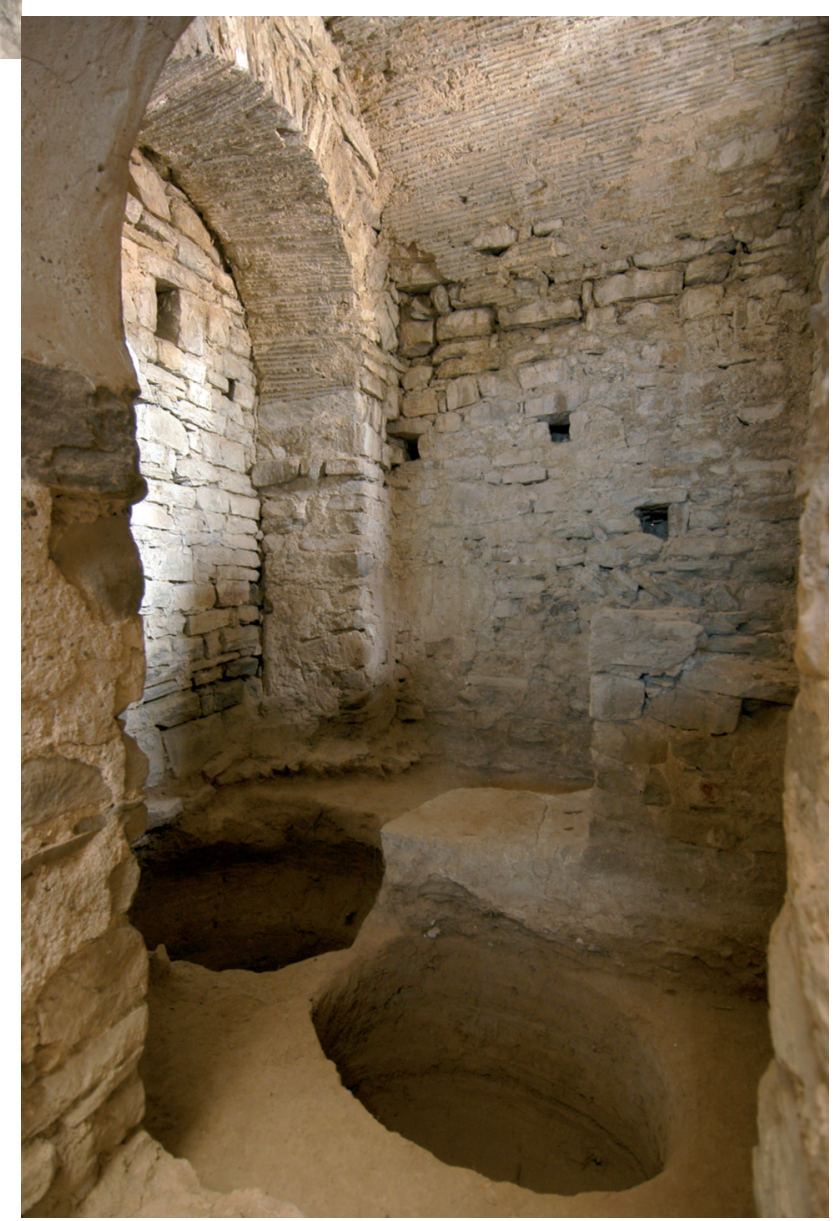




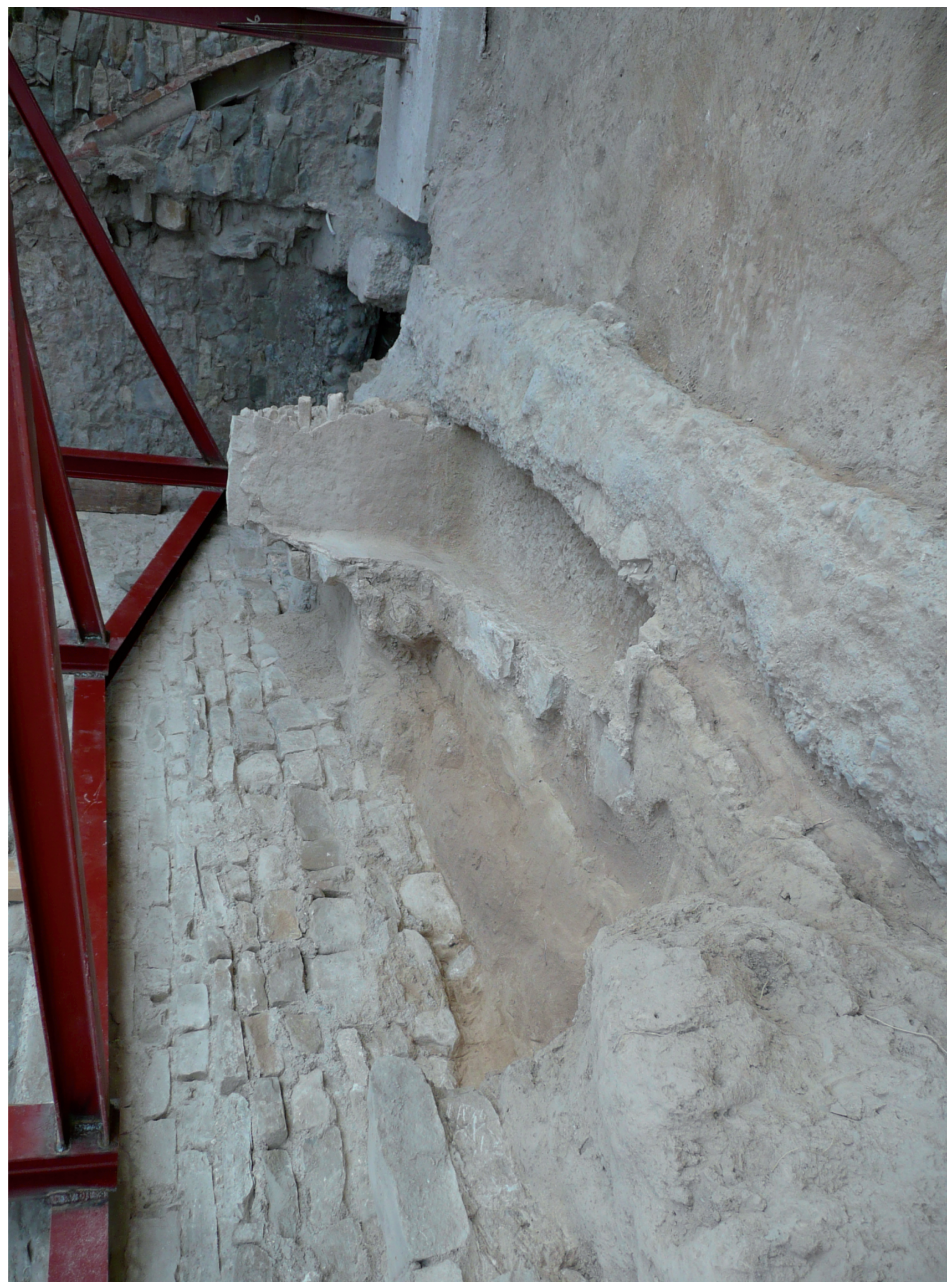

- Figura 13. Vestigios del lacus descubierto a mediodía del templo durante la excavación previa al recalce del muro sur. Foto: fondo documental del SPAL. Alvar Caixal, 2007. 